Journal homepage: http://www.journalijar.com

Journal DOI: $\underline{\text { 10.21474/IJAR01 }}$

RESEARCH ARTICLE
INTERNATIONAL JOURNAL

OF ADVANCED RESEARCH

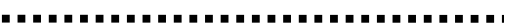

ISSN NO. 2320-5407

\title{
IMPACT OF AN EDUCATIONAL PROGRAM ON MOTHERS' KNOWLEDGE, ATTITUDE AND PRACTICE REGARDING THEIR CHILDREN WITH NOCTURNAL ENURESIS.
}

Zeinab Hassan Hassan Osman and Safaa Abdelazem Osman Ali , Neama Mohamed Fouad Kamel.

\section{Manuscript Info}

Manuscript History:

Received: 12 April 2016

Final Accepted: 19 May 2016

Published Online: June 2016

Key words:

Children, nocturnal enuresis, mothers' knowledge, attitude and practice (KAP Model), toilet training, educational program.

*Corresponding Author

Neama M F Kamel

\begin{abstract}
Introduction:- Child enuresis is a widespread problem that can be upsetting for children and their families.

Design:- The present study is a quasi-experimental one, aimed to provide an educational program for mothers to enhance their knowledge, attitude and practice toward their children with nocturnal enuresis.

Methodology:- This study was conducted at El Fayoum University Hospital and El Fayoum general hospital. The study involved 50 mothers having children with nocturnal enuresis. Tools of the study involved an interview questionnaire to assess socio-demographic characteristics of mothers and their children, mothers' knowledge regarding enuresis as well as their attitude and practice.
\end{abstract}

Results:- showed that, mothers' levels of knowledge about enuresis, attitude and practice have dramatically improved after the educational program implementation with statistically significant differences between pre-post implementation. There were statistically significant relations between mothers' level of knowledge about enuresis, attitude and practice.

Conclusion:- This study recommended that continuous educational program for mothers having children with nocturnal enuresis to update their knowledge and skills about the advancing technology in the health care for their children. This educational program could be delivered through mass media, posters, booklets, MCH centers and individual counseling. Early counseling should be directed to mothers regarding toilet training, especially for families with positive history of enuresis among their members.

Copy Right, IJAR, 2016,. All rights reserved.

\section{Introduction:-}

Childhood nocturnal enuresis (NE) is a health malady that requires immediate attention and management since untreated conditions establish long-term psychosocial hazards to children as well as to their parents. NE is defined in ICD-10 and DSM-V as an involuntary voiding of urine during sleep with a frequency of at least twice a week over the course of at least three months in children aged more than five years in the absence of congenital or acquired defects of the central nervous system or to any structural abnormality of the urinary tract that is abnormal in relation to the child's mental age. As well, it is a common psychosomatic symptom that presents both alone and/or in conjunction with other disorders in children and adolescents (Neveus 2011). ${ }^{(1)}$

In terms of etiology, nocturnal enuresis is a multi factorial problem with biological and psychosocial, aspects interacting with child's risk factors. Acute psychological trauma in early childhood originating from a variety of situations such as disturbed homes, enforced separation from the mother, birth of a sibling and resultant rivalry, bullying at school, parental conflicts, and child abuse, all these occurring beyond 5 years of age are considered as 
risk factors to enuresis. It has been reported that these stressors cause loss of even previously learned urethral sphincter control, particularly in vulnerable children. (Wang et al., 2007). ${ }^{(2)}$

In addition, a family history of nocturnal enuresis is found in most children. The incidence of primary nocturnal enuresis is $77 \%$ among children who have both parents with a history of primary nocturnal enuresis. This rate decreased to $43 \%$ in children who have just one parent with a history of primary nocturnal enuresis and to $15 \%$ in children who have no parental history of primary nocturnal enuresis (Cederblad et al., 2014). ${ }^{(3)}$

As was reported that KAP research approaches are used to understand what people know, believe and do related to a specific topic In health research, this help us to understand the knowledge, attitudes, and practices of a target group, provide data on how to improve quality and accessibility of services, current health and cultural practices. (Launiala 2009). ${ }^{(4)}$

Parental attitudes toward a child's bed-wetting might play important role in relation to successful treatment and potential improvement of negative consequences, and can make the difference in how a child feels about his bedwetting problem. Also, parental attributions for child's enuresis had positive outcomes on parent practices, and parental adjustment. So it is important for nurses to take appropriate intervention for the affected child and family caregiver because of the potential consequences of family stress, social withdrawal, and poor self-esteem. Together, parents and children should work on ways to diminish feelings of failure and look for ways to encourage good feelings (Pashapour et al., 2008). ${ }^{(5)}$

KAP model had been used in the hygiene education field from 1960's to teaching patients how to correct their health behavior in practice, the cognitive learning was focused on the knowledge and the ability of realization; the affective learning means to change the subject's intention, attitude or norms to adjust themselves through hygiene education, the psychomotor learning was focused on cultivating learner's health behavior Launiala (2009) and Chien-Yun, (2011). ${ }^{(4,6)}$

Some parents perceive enuresis as a medical problem, and so tend to seek medical help, in addition ,some parents, having strong religious beliefs tend to seek help from traditional healers. It will be fascinating to explore the knowledge, attitude and practice of a parent towards childhood enuresis in order to plan its preventive and intervention strategies (Gupte, 2009). ${ }^{(7)}$

Educating parents to manage child enuresis is a process can teach the parents some strategies of behavioral therapy such as positive reinforcement which can be initiated by setting up a diary or chart to monitor progress and establishing a system to reward the child for each night that he or she is dry. As well dry bed training also may be part of a comprehensive program to treat enuresis. This therapy involves an age-appropriate explanation of how the brain and the bladder communicate, taking the mystery out of enuresis by educating the child and family, teaching relaxation techniques, and having the child practice imagery of awakening to urinate in the toilet or staying dry all night. It can be combined with an alarm system. Dry-bed training involves waking the child on a progressive schedule at decreasing intervals over several nights (Cederblad et al., 2013). ${ }^{(8)}$

So, the mothers should understand the problem of enuresis, because their role is essential to success in the process of management. They should take responsibility for helping the child to learn the skill of being dry. Mothers are the main caregivers for their children, so nurses as providers of primary health care play a major role in improving knowledge, attitude and practice of mothers regarding their children with enuresis. Also, providing special parenting program was associated with lower levels of parental dysfunction, greater parental self efficacy, less parental distress, and relationship conflict (Meydan, 2012). ${ }^{(9)}$

Psychosocial support is an essential part of stress care which is a psychological burden on mothers. It is important for the mothers to understand that the child is not alone. The child should be included in the treatment plan; this helps increase the child's motivation to become dry and discuss potential strategies with the family to reduce stressors on the child or to help the child cope with the stressors (Anyanwu, et al 2015). ${ }^{(10)}$

\section{Significance of study:-}

There is no an available document regarding to the actual incidence of enuresis among children in Egypt. However, according to a study done in Benha, Egypt, in 2014, it showed that nocturnal enuresis was recorded with a 
prevalence rate of $14.5 \%$ with a higher frequency for boys than girls (16.5\% versus $12.6 \%$ respectively). Enuresis was found to be the most common type of behavior disorder among primary school age children (6-12 years) (Mohammed et al, 2014). ${ }^{(11)}$ Another study done in Egypt at Menoufiya Governorate, in 2012, on the magnitude of the problem of enuresis stated that the prevalence rate of primary enuresis in school children was found to be $11.5 \%$, however secondary enuresis was $3.2 \%$. (Al-Kot \& Deeb 2012) ${ }^{(12)}$

Childhood is the most significant period in every one's life. Every child needs a caring and conducive environment to grow into a potentially healthy human being in every perspective.

The parents play the key role in caring for the child and they should know the causes and consequences of enuresis if not treated. It will help the parents as well as nursing practitioners in caring for the children. Hence, this study was designed to provide an educational program for mothers to enhance their knowledge, attitude and practice toward their children with nocturnal enuresis.

\section{Subjects and Methods:-}

\section{Aim of study:-}

This study aims to provide an educational program for mothers to enhance their knowledge, attitude and practice toward their children with nocturnal enuresis through assessing the mothers' knowledge, attitude and practice toward their children with nocturnal enuresis, developing an educational program for mothers, implementing the educational program to mothers, and finally evaluating the effect of this educational program on mothers having children with nocturnal enuresis.

\section{Hypothesis:-}

The educational program will have a positive effect on mothers' knowledge, attitude and practice regarding their children with nocturnal enuresis

\section{Research Design:-}

A quasi experimental design, one group pre and post test.

\section{Setting of the study:-}

The study was conducted at El Fayoum University Hospital and El Fayoum General Hospital.

Sample: Fifty mothers having children with nocturnal enuresis were recruited for the study sample.

Inclusion criteria:-

* Mothers having children aged 6 to 12 years.

* Mothers willing to participate in the study.

* Mothers who read and write

\section{Exclusion criteria:-}

* Mothers not available at the time of data collection

\section{Sampling technique:-}

A purposive sampling technique was used.

Data collection tools:-

Data were collected using two structured questionnaires after thorough reviewing literature.

Tool I: It consists of sheet for collecting demographic data of both mothers and their children

Tool II: A structured questionnaire to assess the knowledge, attitude and practice of mothers regarding child 's enuresis.

\section{Scoring system:-}

Scoring for Knowledge, Attitude and Practice items, a correct response was scored (1) and the incorrect (zero). For each area, the scores of the items were summed-up and the total divided by the number of the items, giving a mean score for the part. These scores were converted into a percent score. The Knowledge, Attitude and Practice were considered satisfactory if the percent score was $50 \%$ or more and unsatisfactory if less than $50 \%$. 


\section{Contents of the educational program included two parts:-}

Part I: Theoretical part which deals with data needed for providing the mothers having children with nocturnal enuresis with an overview about Enuresis that includes: Introduction about enuresis, definition of Enuresis, types of enuresis, causes of enuresis, complications about Enuresis, and methods of treatment.

Part II: Practical part contains skills needed for improving mothers' patterns of attitude and practice toward children with nocturnal enuresis

\section{Training strategies and media:-}

Different training strategies were used such as; modified lectures, small group discussion, role play, and demonstration and re-demonstration using scenario simulates and real life situations to ensure exposure of all mothers to same learning experience.

Evaluation phase: immediate post program implementation of the program, a post test was carried out in March 2016 to assess the effectiveness of the educational program on the mothers having children with nocturnal enuresis.

The same data collection tools were used for this purpose.

\section{Methods:-}

* Official letters of approval were taken from the Dean of the Faculty of Nursing, Fayoum University to the directors of El Fayoum University Hospital and El Fayoum general Hospital to explain the purpose and importance of the study

* A study tool was developed via thorough reviewing literature and tested for content validity by 5 experts in psychiatric and pediatric nursing department.

* Mothers were informed about the aim of the study

- Informed oral consent was obtained from the subject of the study for collecting needed data and confidentiality will be assured and maintained.

* A pilot study for the questionnaires was conducted on (10\%) of the subjects that were not included in the actual study to assess the time needed to fulfill the questionnaires, feasibility and clarity of the tools. In the light of the findings of the pilot study, no changes occurred in the tools.

- Subjects involved in the study were interviewed and assessed two times before program to obtain baseline data and after implementing a program to evaluate the effectiveness of acquaintance sessions.

* The researchers explained the purpose of the study before implementing the program and distributed the tools to be filled in by all mothers whom recruited for the study sample, the researchers were present to assure that all questions were completed. Filling in the tools took 25 minutes for each subject included in the study.

\section{Duration of the study:}

11 months, from June 2015 to May 2016, Data collection was carried out at the beginning of June 2015 to October 2015 , followed by implementation of the program in about ten sessions for mothers at the pediatric clinics in El Fayoum University Hospital and El Fayoum General Hospital Six months after the end of the program, a post test was carried out in April 2016 to assess the effectiveness of the educational program on the mothers..

\section{Ethical considerations:-}

The researchers assured for every mother involved in the study sample, that participation is voluntary and that they have the right to withdraw from the study at any time without giving any reason. The researcher clarified that all information would be used only for scientific research and for the mothers' benefits.

\section{Statistical Design:-}

Statistical presentation and analysis of data of the present study were carried out using mean, standard deviation, unpaired mothers t-test, linear correlation coefficient and chi-square tests by SPSS (Statistical Package for the Social Science) version 20.0

\section{Limitations and strengths of the study:-}

This study had several limitations. Firstly, the sample was relatively small and the result cannot be generalized. Secondly, It has been taken a long time to collect subjects because the little subject who search the treatment in society of El Fayoum City, Egypt.

Despite these limitations, the current study used pre and post design so results can be generalized, the present study sheds new light on address different variables affecting mother knowledge, attitude and practice. The study used 
KAP Model to change as a base of surveying and implementing an education program which made it more stronger one.

\section{Results:-}

Table (1) revealed that, the majority of mothers (86\%) their age were in the group 30 or more years and the majority of fathers $(64 \%)$ were in the age group 40 or more years. This table also showed that less than two thirds of the mothers had intermediate education (68\%) and more than half $(54 \%)$ of the fathers had a primary / preparatory education. More than half of the mothers were housewives (54\%) and less than three quarters of fathers were unemployed (72\%). It can be noticed $70 \%$ of the studied subjects had positive family history. Only $14 \%$ of the children had divorced or widowed parents.

Table 1:- Demographic characteristics of the mothers having children with nocturnal enuresis in the study sample $(n=50)$

\begin{tabular}{|c|c|c|c|}
\hline \multicolumn{2}{|c|}{ Family Characteristics } & \multirow{2}{*}{$\begin{array}{c}\text { Frequency } \\
\end{array}$} & \multirow{2}{*}{$\begin{array}{c}\text { Percent } \\
14.0 \\
\end{array}$} \\
\hline Mother age & $<30$ & & \\
\hline & $30+$ & 43 & 86.0 \\
\hline \multirow[t]{2}{*}{ Father age } & $<40$ & 18 & 36.0 \\
\hline & $40+$ & 32 & 64.0 \\
\hline \multirow[t]{2}{*}{ Mother education } & primary & 16 & 32.0 \\
\hline & Intermediate & 34 & 68.0 \\
\hline \multirow[t]{2}{*}{ Mother job } & Housewife & 27 & 54.0 \\
\hline & Worked & 23 & 46.0 \\
\hline \multirow[t]{3}{*}{ Father education } & primary & 27 & 54.0 \\
\hline & Intermediate & 9 & 18.0 \\
\hline & University & 14 & 28.0 \\
\hline \multirow[t]{2}{*}{ Father job } & Unemployed & 36 & 72.0 \\
\hline & Working & 14 & 28.0 \\
\hline \multirow[t]{2}{*}{ Current marital } & Married & 43 & 86.0 \\
\hline & Divorced / widowed & 7 & 14.0 \\
\hline \multirow[t]{2}{*}{ Positive family history of enuresis } & Yes & 35 & 70.0 \\
\hline & No & 15 & 30.0 \\
\hline
\end{tabular}

Table (2) revealed that more than two fifth of children (42\%) were in the age group $6-<8$ years. Male children constituted $(64 \%)$ and $50 \%$ were first in birth rank. The duration of illness was less than one year in $28 \%$ of children. Slightly more than two thirds of children (68\%) have a title or stigma related to enuresis.

Figure (1) illustrated statistically significant improvements in mothers' knowledge, practice and attitude about child enuresis at the post-intervention phase $(\mathrm{p}<0.001)$.

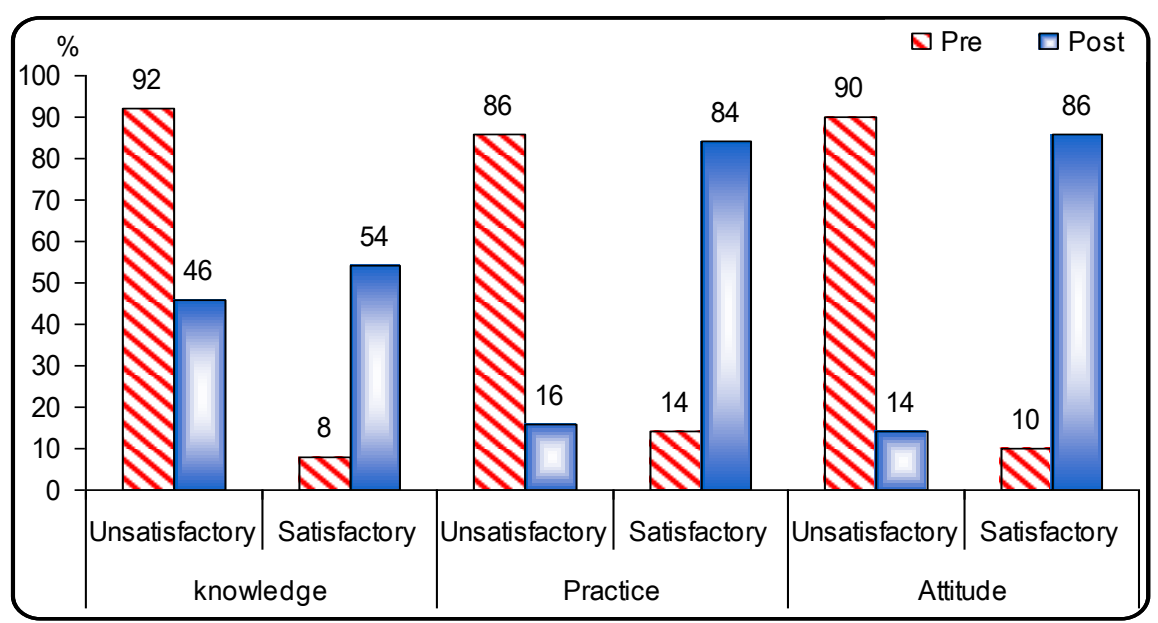


As regards the relation between mothers' knowledge with their practice and attitude toward child enuresis, table (3) pointed at a statistically significant association between pre-post educational program implementation $(\mathrm{p}=0.001)$.

Table 3:- Relations between mothers' knowledge about child enuresis and their practice and attitude before and after program implementation

\begin{tabular}{|c|c|c|c|c|c|c|c|c|c|c|}
\hline \multicolumn{3}{|c|}{ Items } & \multicolumn{8}{|c|}{ Knowledge } \\
\hline & & & \multicolumn{2}{|c|}{ Unsatisfactory } & \multicolumn{2}{|c|}{ Satisfactory } & \multicolumn{2}{|c|}{ Total } & \multicolumn{2}{|c|}{ Test } \\
\hline & & & No & $\%$ & No & $\%$ & No & $\%$ & $X^{2}$ & P-value \\
\hline \multirow[t]{4}{*}{ Practice } & \multirow[t]{2}{*}{ Before } & Unsatisfactory & 43 & 86.0 & 0 & 0.0 & 43 & 86.0 & \multirow[t]{2}{*}{26.708} & \multirow[t]{2}{*}{$<0.001 *$} \\
\hline & & Satisfactory & 3 & 6.0 & 4 & 8.0 & 7 & 14.0 & & \\
\hline & \multirow[t]{2}{*}{ After } & Unsatisfactory & 8 & 16.0 & 0 & 0.0 & 8 & 16.0 & \multirow[t]{2}{*}{11.180} & \multirow[t]{2}{*}{$<0.001 *$} \\
\hline & & Satisfactory & 15 & 30.0 & 27 & 54.0 & 42 & 84.0 & & \\
\hline \multirow[t]{4}{*}{ Attitude } & \multirow[t]{2}{*}{ Before } & Unsatisfactory & 41 & 82.0 & 4 & 8.0 & 45 & 90.0 & \multirow[t]{2}{*}{0.483} & \multirow[t]{2}{*}{0.487} \\
\hline & & Satisfactory & 5 & 10.0 & 0 & 0.0 & 5 & 10.0 & & \\
\hline & \multirow[t]{2}{*}{ After } & Unsatisfactory & 7 & 14.0 & 0 & 0.0 & 7 & 14.0 & \multirow[t]{2}{*}{9.555} & \multirow[t]{2}{*}{$0.002 *$} \\
\hline & & Satisfactory & 16 & 32.0 & 27 & 54.0 & 43 & 86.0 & & \\
\hline
\end{tabular}

Table (4) demonstrated statistically significant moderate positive correlation among mothers' knowledge and their practice $(\mathrm{r}=0.546)$ and attitude toward child enuresis $(\mathrm{r}=0890)$ post program. Meanwhile, the crowding index score had a statistically significant moderate negative correlation with knowledge $(\mathrm{r}=-0.310)$ and each of the practice and attitude (- $0.743 \&-0.660$ respectively). The table also revealed statistically significant moderate to strong negative correlations among the scores of knowledge, practice and attitude and each of frequency of bed wetting per week and per night, the highest being between practice and frequency of bed wetting per week $(\mathrm{p}=0.880)$.

Table 4:- Correlations among mothers' knowledge, practice, attitude pre/post scores and the socio-demographic characteristics

\begin{tabular}{|l|c|c|c|c|c|c|}
\hline \multirow{2}{*}{ Items } & \multicolumn{6}{|c|}{ Spearman Rank Correlation Coefficient } \\
\cline { 2 - 7 } & \multicolumn{2}{|c|}{ Knowledge } & \multicolumn{2}{c|}{ Practice } & \multicolumn{2}{c|}{ Attitude } \\
\cline { 2 - 7 } Before & $\mathrm{r}$ & $\mathrm{P}-\mathrm{value}$ & $\mathrm{r}$ & $\mathrm{P}$-value & $\mathrm{r}$ & P-value \\
\hline Practice & & & & & & \\
\hline Attitude & 0.837 & $<0.001^{*}$ & & & & \\
\hline Age of mother & 0.438 & $<0.001^{*}$ & 0.422 & $0.002^{*}$ & & \\
\hline Age of father & 0.317 & $0.025^{*}$ & 0.775 & $<0.001^{*}$ & 0.435 & $0.002^{*}$ \\
\hline Crowding index & 0.469 & $<0.001^{*}$ & 0.865 & $<0.001^{*}$ & 0.494 & $<0.001^{*}$ \\
\hline Frequency of bedwetting weekly & -0.222 & 0.121 & -0.091 & 0.529 & -0.668 & $<0.001^{*}$ \\
\hline Frequency of bedwetting nightly & 0.159 & $0.004^{*}$ & -0.278 & 0.051 & 0.580 & $<0.001^{*}$ \\
\hline After & & & -0.324 & $0.022^{*}$ & 0.413 & $0.003^{*}$ \\
\hline Practice & 0.473 & $<0.001^{*}$ & & & & \\
\hline Attitude & 0.890 & $<0.001^{*}$ & 0.038 & 0.792 & & \\
\hline Age of mother & 0.098 & 0.499 & 0.066 & 0.647 & 0.224 & 0.117 \\
\hline Age of father & 0.097 & 0.501 & 0.026 & 0.855 & 0.174 & 0.227 \\
\hline Crowding index & -0.310 & $0.029^{*}$ & -0.743 & $<0.001^{*}$ & -0.660 & $<0.001^{*}$ \\
\hline Frequency of bedwetting weekly & -0.387 & $0.006^{*}$ & -0.880 & $<0.001^{*}$ & -0.805 & $<0.001^{*}$ \\
\hline Frequency of bedwetting nightly & -0.371 & $0.008^{*}$ & -0.600 & $<0.001^{*}$ & -0.414 & $0.003^{*}$ \\
\hline
\end{tabular}

(*) Statistically significant at $p<0.05$

Multivariate analysis in table (5) revealed that baseline scores of mothers' work, age of child were the statistically significant independent positive predictors of the post-intervention knowledge score. Meanwhile, duration of child enuresis, weekly frequency of bedwetting occurrence and frequency of bedwetting in the night score turned to be negative predictors of the knowledge score. The model explains 59\% of the variation in this score. 
Table 5:- Best fitting multiple linear regression model for the improvement in mothers' knowledge score after the intervention

\begin{tabular}{|l|c|c|c|c|c|c|c|}
\hline \multirow{2}{*}{ Constant } & \multicolumn{2}{|c|}{$\begin{array}{c}\text { Unstandardized } \\
\text { Coefficients }\end{array}$} & $\begin{array}{c}\text { Standardized } \\
\text { Coefficients }\end{array}$ & t-test & P-value & \multicolumn{2}{c|}{$\begin{array}{c}95.0 \% \text { Confidence } \\
\text { Interval for B }\end{array}$} \\
\cline { 2 - 8 } & B & Std. Error & Beta & & & $\begin{array}{c}\text { Lower } \\
\text { Bound }\end{array}$ & $\begin{array}{c}\text { Upper } \\
\text { Bound }\end{array}$ \\
\hline Mothers' work & 0.889 & 0.171 & 1.633 & 5.192 & $<0.001^{*}$ & 0.544 & 1.234 \\
\hline Age of child & 0.444 & 0.150 & 1.444 & 2.962 & $0.005^{*}$ & 0.142 & 0.747 \\
\hline $\begin{array}{l}\text { Duration of } \\
\text { child enuresis }\end{array}$ & -0.148 & 0.049 & -0.807 & -3.027 & $0.004^{*}$ & -0.247 & -0.050 \\
\hline $\begin{array}{l}\text { weekly number } \\
\text { of bedwetting } \\
\text { occurrence }\end{array}$ & -0.100 & 0.038 & -0.345 & -2.638 & $0.011^{*}$ & -0.177 & -0.024 \\
\hline $\begin{array}{l}\text { Number of } \\
\text { bedwetting } \\
\text { occurrence in } \\
\text { the night }\end{array}$ & -0.166 & 0.074 & -0.293 & -2.243 & $0.030^{*}$ & -0.314 & -0.017 \\
\hline \multicolumn{2}{|l|}{ Dependent Variable: Knowledge } & & & & & & \\
\hline
\end{tabular}

\section{R-square $=0.56 \quad$ Variables entered and excluded: Mother Education, the child has a stigma or title}

Table (6) presented the best fitting multiple linear regression model for practice scores. It identifies that the statistically significant positive independent predictors of mothers' practice scores were the mother's work, and age of child, stigma or title to the child score. On the other hand, the frequency of enuresis weekly and nightly score were a negative predictor of mothers' Practice scores. Other characteristics had no influence on the practice scores of mothers.

Table 6:- Best fitting multiple linear regression model for the improvement in mothers' practice score after the intervention

\begin{tabular}{|l|c|c|c|c|c|c|c|}
\hline \multirow{2}{*}{ Constant } & \multicolumn{2}{|c|}{$\begin{array}{c}\text { Unstandardized } \\
\text { Coefficients }\end{array}$} & $\begin{array}{c}\text { Standardized } \\
\text { Coefficients }\end{array}$ & t-test & \multicolumn{2}{c|}{ P-value } & \multicolumn{2}{c|}{$\begin{array}{c}95.0 \% \text { Confidence } \\
\text { Interval for B }\end{array}$} \\
\cline { 2 - 8 } & B & Std. Error & Beta & & & $\begin{array}{c}\text { Lower } \\
\text { Bound }\end{array}$ & $\begin{array}{c}\text { Upper } \\
\text { Bound }\end{array}$ \\
\hline Mothers' work & 1.556 & 0.238 & 2.234 & 6.522 & $<0.001^{*}$ & 1.075 & 2.036 \\
\hline child age & 0.778 & 0.126 & 1.975 & 6.195 & $<0.001^{*}$ & 0.525 & 1.031 \\
\hline $\begin{array}{l}\text { Duration of } \\
\text { child enuresis }\end{array}$ & -0.259 & 0.041 & -1.105 & -6.332 & $<0.001^{*}$ & -0.342 & -0.177 \\
\hline $\begin{array}{l}\text { Child title or } \\
\text { stigma }\end{array}$ & 0.259 & 0.064 & 0.349 & 4.027 & $<0.001^{*}$ & 0.130 & 0.389 \\
\hline $\begin{array}{l}\text { Weekly } \\
\text { number of } \\
\text { bedwetting }\end{array}$ & -0.176 & 0.040 & -0.472 & -4.352 & $<0.001^{*}$ & -0.257 & -0.094 \\
\hline $\begin{array}{l}\text { Nightly } \\
\text { number of } \\
\text { bedwetting }\end{array}$ & -0.290 & 0.078 & -0.401 & -3.701 & $<0.001^{*}$ & -0.448 & -0.132 \\
\hline Dependent Variable: Practice & & & & & & \\
\hline
\end{tabular}

R-square $=0.31 \quad$ Variables entered and excluded: Father age, mother education.

\section{Discussion:-}

Most of the published studies regarding bedwetting assess the psychological impact of this problem on the children rather than on their families. In the present study, the researchers investigated the impact of implementing educational program on mothers' knowledge, attitude and practice. So it is crucial to investigate and manage as soon as possible any misconceptions among the parents (Walle \& Erratum 2013). ${ }^{(13)}$ 
According to the result of the current study, the majority of the mothers were in the third decade of age, more than half were housewives and more than two thirds having intermediate education, also more than three fifths of the fathers was 40 years or more and less than three quarters are without job and more than half had basic education. The present study results also revealed that the highest percentage of children with enuresis is quite common in the society of El Fayoum Governorate; where education is a critical factor that may affect the mothers' ability to use booklet to gain the required information although they are having enough time while may give them an opportunity to provide good care and apply gained practice about child enuresis. A similar finding was demonstrated in the study of Elbahnasawy and Elnagar (2015) ${ }^{(14)}$ who proved that a higher relative risk of enuresis in children was observed in families with a father with a lower education and a mother with a relatively lower education. In the same line, another previous research carried out by Inan, et al. (2008) reported that the higher prevalence of enuresis occurs in families where mother has a lower level of education. ${ }^{(15)}$

In the current study, more than a tenth of mothers are divorced or widowed; this explained that enuresis is one of the manifestation of psychological/emotional factors such as divorce or death of parents. This is in agreement with Saleh et al. (2015), in Iraq who mentioned that there is a close relationship between the disturbed family environment and the frequency of enuresis, and this prevalence is $29.4 \%$ among disturbed families. ${ }^{(16)}$

Considering family history of enuresis, the study revealed that more than two thirds of children were having a positive family history of enuresis. This finding may be attributed to the presence of genetic factors in the occurrence of nocturnal enuresis, where consangious marriage in El Fayoum locality may hasten the genetic basis of this disease. This finding is congruent with Aljefri et al. (2013) ${ }^{(17)}$, in Saudi Arabia, and Ismail et al. (2013) ${ }^{(\mathbf{1 8})}$, in Egypt who postulated that enuresis commonly runs in families and the incidence of it among children increases when the father and/or mother have appositive history of bed wetting; 77\% among children who have both of parents with a history of primary nocturnal enuresis. This rate decreased to $43 \%$ in children who have just one parent with a primary nocturnal enuresis and to $15 \%$ in children who have no parental history of primary nocturnal enuresis.

As regards gender of children, a higher percentage of boys than girls was detected among the children with enuresis. This finding may be attributed to the culture of mothers of enuretic children residing rural areas as El Fayoum City who are over interested in boys more than girls, accompanying the boys to seek medical treatment for them. This is in agreement with Ali et al. (2009) ${ }^{(19)}$, who found that nocturnal enuresis is more prevalent and prolonged in boys than in girls. In this line Aljenaei, (2009) ${ }^{(20)}$ pointed out that boys over numbered girls and this was explained by wariness of parents for their boys, while their daughters for fear that the condition might affect a marriage. However, it may be attributed to difference in anatomical structure of the urinary system between males and females.

With regard to the age of children in this study, sample almost was equally alienated at the age of 6 to less than 8 years. This finding may be due to an inadequate experience and knowledge of a mother about correct toileting and lack of awareness about how to deal with their children. The study results also mentioned that the incidence rates of enuresis decrease gradually with increasing age. This finding is similar to that of another study conducted in Egypt by Elsayed et al. (2012), who found that the highest incidence of enuresis in a sample of Egyptian primary school children was among children in the age 8-10 years. ${ }^{(21)}$

The current study revealed that children ranked between first and second or higher in birth order. Obviously, the mothers of those children having many children with additional loads in providing care to the enuretic child as well as siblings which increases the burden of mothers in addition to lack of parents' awareness about psychological factors related to the occurrence of enuresis, also the repercussions of families with a lot of kids were found not only on the economic conditions, but also on family dynamics, level of medical and psychological care for enuretic child, as well as family conflicts. In agreement with this, Yousef et al. (2011) in Yemen and Hashem et al. (2013), in Iran reported that the higher frequency of enuresis was observed in children of lower socioeconomic status especially in cases of inadequate clothes and large crowded families. ${ }^{(22,23)}$

As regards the period of child enuresis in years, less than one quarter of children was suffering from enuresis for 6 years to less than 8 . This may be due to that the age of enuretic children at the present study was 6 to 12 years; school age children and entering school may be stressful event for them. This finding is in agreement with Salih et al. (2013) ${ }^{(24)}$ in Sudan and with Mohammed et al. (2014) in Egypt. ${ }^{(1)}$ 
According to the mothers' knowledge about children's enuresis in El Fayoum city in Egypt, the current study, findings reported statistically significant improvements at the post-intervention phase at p-value $<0.001$. Mothers' knowledge has been changed positively after the application of the educational program. This indicates that they were in great need for information, and that the educational program was successful in achieving their needs. The study outcomes point to the application of the educational program that can be improving the mothers' knowledge and justifying the research hypothesis in that it will have a positive effect on mothers' knowledge. This finding is in congruence with EISaid, (2013) ${ }^{(25)}$, who mentioned that the characteristics of the health education program were custom-tailored to real identified mothers' needs. As well, the findings of this study were in accordance with those of Najeeb and Moulhee (2012) ${ }^{(26)}$, who stated that the structured educational program significantly reduced relapse rates of nocturnal enuresis, achieving optimum and excellent outcomes in their study conducted in Yemen.

Additionally, the booklet provided to mothers in the present study helped in their acquisition and retention of knowledge which might be an important reason underlying the success of the program.

According to mothers' attitude regarding their child with enuresis, there is statistically significant difference between pre and post program phases. Before program implementation, mothers believed that children with enuresis had a little or no control over a certain stressful situations expressed by varying behavior, including bed wetting, child unconsciously defying them by wetting the bed, and also many mothers considered enuresis as a benign condition that is self limiting. After program intervention, a positive attitude of mothers was shown towards their children toilet training as reported by the majority of them. Mothers' attitudes toward bedwetting (desire \& motivation to change) influence the likelihood of treatment success; also mothers positive attitude and motivation to be dry are important components of treatment for instilling confidence, decreasing complications and enhancing compliance .This finding was supported by that of Cederblad et al. (2015) ${ }^{(27)}$ who in a very recent study emphasized on toilet training schedule, which is a simplified method of treatment, reducing time, costs and extending the availability of effective treatment to families with limited social and financial resources. In addition, parental attitude is commonly associated with child and punitiveness, neglect, over submissiveness, perfectionism and habit formation.

In addition, Caldwell et al. (2013) ${ }^{(28)}$ described behavioral intervention as generally effective strategies through behavioral therapy to children with enuresis that gives reward as an encouragement for their children to control urine, also moral reward increases the children's feelings of love and empathy and increases self esteem. Rewarding the child for being dry, especially at night is a useful step. The educational program led to increased mothers' confidence in their knowledge and practice, and to initiate discussion about emotional issues.

In relation to the mothers' attitude related to treatment of enuresis, this study results revealed that toilet-training is the first choice for mothers followed by psychological treatment and pharmacological treatment, then and finally mechanical devices as reported by them. This may be due to that the psychological treatment needs to devote efforts from parents to follow up the session of therapy with the psychiatrist. This is in addition to the mechanical devices which are expensive tools for treatment and nearly available while toilet training was a highly successful method for treatment, but when using at night they may interrupt the mothers' sleeping and many children refuse to awake at night and respond to void continuously. This result is consistent with that of Kwak et al. (2011) and Caldwell et al. (2016) who mentioned that pharmacological therapy continues to be the preferred treatment for both physicians and families. ${ }^{(29,30)}$ As well, Gökçe et al. (2014) reflect the importance of providing treatment options which are easy for the patients and their families to follow. So, the first choice of treatment should be the one most acceptable to the family. ${ }^{(31)}$

As regards mothers' practice regarding child enuresis, there is a statistically significant difference between the pre and post test phases at p-value $<0.001$, as the researchers apply the educational program, this can give educational opportunities to the mothers with informative basis. So, the mothers in the current study who became pre-occupied with applying gained practices as increasing child fluid intake in the morning more than one liter, and don't permit child to take their last drink just before bedtime and eating large amount of food rich in salt in lunch that make the child drink more in the night. This result comes in parallel with another study done by Ahmed (2010) ${ }^{(32)}$ who clarified that applying this program and giving mothers an opportunity to continue and promote their practice lead to change their child lifestyle, taking the child to bathroom to void prior to bed time, waking up the child at intervals through the night and rewarding and praising the child for every dry night are the most applicable practices. In addition, Mohammed, (2014) identified that lighting near the bathroom, waking the child at night to void, non- 
humiliation and fluid restriction techniques were the main methods of caring for enuretic children as reported in majority of mothers $(80.0 \%){ }^{(33)}$

In this respect, El-Shaarawy (2015) ${ }^{(34)}$ who recently conducted his study in Egypt, mentioned that the program was a package intervention that included a written contingency contract, positive reinforcement for dry nights, removal of pull-ups, and a morning cleanup procedure when nocturnal enuresis occurred. As well, the mothers who have poor practices, their children have poor care and inadequate hygienic measures toward nocturnal enuresis. In a previous study, done by Hansakunachai et al. (2005), they postulated that almost three quarters of the mothers used herbs or traditional medicine to treat enuresis. ${ }^{(35)}$

There were highly statistically significant correlations between mothers' knowledge, practice and attitude $(\mathrm{P}<$ 0.001). This revealed that the mothers who have a good knowledge about enuresis also had a positive attitude toward enuresis and proper practice in dealing with their children with enuresis. On the other hand Duraphe (2015) clarified that a positive attitude was alleviated by good knowledge, and proper practice was alleviated by good knowledge together with positive attitude too. Such informational support enables the mothers by providing them with information, guidance or advice that they can use good practice and manage their children's enuresis. (36)

On the other hand, the present study findings revealed significantly higher levels of satisfactory knowledge with the male child, the association with the male gender of the child may be explained by the known preference for boys in the Egyptian community as in other countries of the developing world. The results demonstrated low percentages at the pre-intervention phase; also the mothers' practice scores were significantly higher with higher levels of parents' education, higher fathers' job category, and sufficient income as mentioned by DiBianco et al. (2015). ${ }^{(37)}$

Moreover, Spearman rank correlation coefficient analysis demonstrated that mothers' knowledge improved their practice and attitude. These might be considered as the intermediate factors through which the knowledge had its positive influence on mothers' practice and attitude, for instance, the knowledge gained concerning enuresis. These findings are in congruence with previous studies as that done by Stover et al. (2008). ${ }^{(38)}$

Furthermore, mothers' knowledge, practice and attitude were negatively correlated with each of frequency of bed wetting weekly and per night. This means that mothers with satisfactory knowledge scores easily practice the gained information more effectively, and their children experienced less bed wetting rate per week and per night. These results were in accordance with similar studies done in Nigeria, which reported that mothers with unsatisfactory knowledge scores have their children have experienced more bed wetting rate per week and per night (Senbanjo et al., 2011). ${ }^{(39)}$ On the same line, Mota and Barros (2008) identified that the health education is considered the most effective and important nursing role in improving the mothers' practice and attitude, which indeed lead to that mothers feel more in control and help them serve as advocates for their beloved children. ${ }^{(40)}$

\section{Conclusion:-}

The findings of the present study reached to the following conclusion:

The main results showed that, mothers' level of knowledge, practice and attitude about child enuresis have dramatically improved after the educational program implementation with statistically significant differences between pre-post implementation. In the same line, improving the mothers' level of knowledge is necessary aspect in managing their children with enuresis which consequently affecting their attitudes and practice.

\section{Recommendations:-}

Based on the results of the present study, the following recommendations are suggested.

* Development of a health educational program for mothers of children with enuresis to update their knowledge and skills about the advancing technology in the health care of their children. This educational program could be delivered through mass media, posters, booklets, MCH centers and individual counseling.

* Early counseling and investigation should be directed to mothers regarding toilet training, especially for families with positive history of enuresis among their members.

* Educational programs should be carried out by the nurses in order to increase public health awareness about the nature of enuresis and provide mothers with information related to risk factors of enuresis in the natural development of bladder control, methods of prevention and child psychological needs. 


\section{References:-}

1. Neveus, T. (2011): Nocturnal enuresis - theoretic background and practical guidelines. Pediatr Nephrol; 26:1207-14.

2. Wang, Q.W., Wen, J.G., Song, D.K., Su, J., Zhu, Q.H., Liu, K., Che, Y.Y., Du, A.M. \& Wei, J.X. ( 2007): Bed-wetting in Chinese children: epidemiology and predictive factors. Neurourol Urodyn; 26(4):512-7.

3. Cederblad, M., Sarkadi, A., Engvall, G., \& Nevéus, T. (2014): Infrequent enuresis, the uninvestigated majority - comparisons between children with enuresis of varying severity. J Pediatr Urol, (14) 513.

4. Launiala, A. (2009): How much can a KAP survey tell us about people's knowledge, attitudes and practices ? Some observations from medical anthropology on malaria in pregnancy in Malawi Background: KAP surveys. Anthropology Matters Journal, 11(1), 1-13.

5. Pashapour, N., Golmahammadlou, S., \& Mahmoodzadeh, H. (2008): Nocturnal enuresis and its treatment among primary-school children in Oromieh, Islamic Republic of Iran. Health J; 14(2):18-23.

6. Chien-Yun, D., Wan-Fei, C., Yu-Hsi, Y., \& Chia-Hung, Y. (2011): A Study on Modification of Knowledge, Attitude and Practice on Vocational High School Electronics Courses Integrated with Nanotechnology Concept. International Journal of Thermal and Environmental Engineering, 4(1), 73-79. http://doi.org/10.5383/ijtee.04.01.011.

7. Gupte, S. (2009): A short textbook of pediatrics (11th ed.). Jaypee Brothers Medical Publishers. : 50-51.

8. Cederblad, M., Nevéus, T., Åhman, A., Österlund Efraimsson, E., \& Sarkadi, A. (2013): "Nobody asked us if we needed help". Swedish parents experiences of child enuresis. J Pediatr Urol,; 10:74-9.

9. Meydan, E.A. (2012): The quality of life of mothers of children with monosymptomatic enuresis nocturia. International Urology Nephrology; 44: (3), 655-659.

10. Anyanwu, O.U., Ibekwe, R.C. \& Orji, M.L. (2015): Nocturnal enuresis among Nigerian children and its association with sleep, behavior and school performance. Indian Pediatrics; 52 july 15.

11. Mohammed, A.H., Saleh, A.G., \& Al Zoheiry, I. (2014): Frequency of bedwetting among primary school children in Benha City, Egypt. The Egyptian Journal of Medical Human Genetics;15: 287-292.

12. Al-Kot, M., \& Deeb, M. (2012): Nocturnal enuresis among school children in Menoufia Governorate: A hidden problem. J Am Sci; 8(1):328-34.

13. Walle, V. J. \& Erratum, T.O. (2013): Practical consensus guidelines for the management of enuresis. Eur J Pediatr; 172:2857.

14. Elbahnasawy, H.T., \& Elnagar, M.A. (2015): Psychological impact of nocturnal enuresis on self-esteem of school children. American Journal of Nursing Research; 3, (1) 14-20. Available online at: http://pubs.sciepub.com/ajnr/3/1/4 @ Science and Education Publishing DOI: 10.12691/ajnr-3-1-4.

15. Inan, M., Tokuc, B., \& Aydiner, C. Y. (2008): Personal characteristics of enuretic children: An epidemiological study from South-East Europe. Urologia International; 81(1):47-53.

16. Saleh, A. A., Atheer, J. \& Al-Saffar, A. (2015): Nocturnal enuresis and its relation to child's behavior in a sample of children from Baghdad, Iraq, AL-Nahrain University, Baghdad, Iraq. Iraqi JMS. 13: (1). ISSN 16816579 .

17. Aljefri, H.M, Basurreh, O.A., \& Yunus, F., (2013): Nocturnal enuresis among primary school children. Saudi J Kidney Dis Transplant; 24(6): 1233-41.

18. Ismail, A., Abdelbasser, K., Abdel-moneim, M. (2013): Prevalence and risk factors of primary nocturnal enuresis in primary school children in Qena Governorate, Egypt. Egyptian J Neurol Psychiat Neurosurg; 50(2): 163-9.

19. Ali, G., Gulsen, G., \& Yasemin, A., (2009): The epidemiology and factors associated with nocturnal enuresis among boarding and daytime school children in southeast of Turkey: A cross sectional study. BMC Public Health; 9, 35.

20. Aljenaei, A. (2009): Prevalence of nocturnal enuresis among Qatari students aged 6 to 12 years. Doha, Qatar. PP.7-8.

21. Elsayed, E., Abdall, M., Eladl, M., Gaber, A., Siam, A. \& Abdelrohman, H. (2012): Predictors of severity and treatment response in children with monosymptomatic nocturnal enuresis receiving behavioral therapy. Journal of Pediatric Urology; 8: 29-34

22. Yousef, K.A., Basaleem, H.O., binYahiya, M.T.( 2011): Epidemiology of nocturnal enuresis in basic schoolchildren in Aden Governorate, Yemen. Saudi J Kidney Dis Transplant; 22(1): 167-73. 
23. Hashem, M., Morteza, A., Mahammed, K., \& Ahmed, N. (2013): prevalence of nocturnal enuresis in school aged children the role of personal and parents related socio- economic and educational factors, Iran Journal Pediatric, 33(1) 59-64.

24. Salih, K.M., Ahmed, F.E., \& Omer, Y.I. (2013): Characteristics and etiological factors of nocturnal enuresis in Sudanese children. Am J Med Dental Sci; 1(2): 40-5

25. Elsaid, S.M. (2013): Impact of educational Programme on self Esteem of children with nocturnal enuresis and their mother's anxiety and depression, D.N.Sc. Thesis in Psychiatric Nursing, El Menoufya University.

26. Najeeb, M.S. \& Moulhee (2012): Effect of the educational program upon parents' knowledge of nocturnal enuretic children. World Journal of Medical Sciences; 7 (3): 137-146, ISSN 1817-3055.

27. Cederblad, M., Sarkadi, A., Engvall, G., \& Nevéus, T. (2015): No effect of basic bladder advice in enuresis. A randomized controlled trial. J Pediatr Urol. (In press)

28. Caldwell, P.H., Nankivell, G., \& Sureshkumar, P. (2013): Simple behavioral interventions for nocturnal enuresis in children. Cochrane Database Syst Rev; 7:CD003637.

29. Kwak, K.W., Park, K.H., \& Baek, M. (2011): The efficacy of enuresis alarm treatment in pharmacotherapyresistant nocturnal enuresis. Urology; 77:200.

30. Caldwell, P.H., Sureshkumar, P., \& Wong, W.C. (2016): Tricyclic and related drugs for nocturnal enuresis in children. Cochrane Database Syst Rev; 1:CD002117.

31. Gökçe, M.İ., Hajıyev, P., \& Süer, E., (2014): Does structured withdrawal of desmopressin improve relapse rates in patients with monosymptomatic enuresis? J Urol; 192:530.

32. Ahmed, M.M. (2010): Mothers care for their children regarding enuresis in rural areas, D.N.Sc. Thesis in Community health nursing. Faculty of nursing, Benha University.

33. Mohammed, A.M. (2014): The effectiveness of psychological counseling program in reducing bedwetting in children and psychological problems associated with case of mothers of infected children. Alribab Village, Gezira State, Sudan study.

34. El-Shaarawy, S.F. (2015): Efficacy of cognitive-behavioral therapy of enuresis among a sample of enuresis children and adolescents: An experimental study. Faculty of Education, Benha University.

35. Hansakunachai, T., Ruangdaraganon, N., Udomsubpayakul, U., Sombuntham, T., \& Kotchabhakdi, N. (2005): Epidemiology of enuresis among school-age children in Thailand. J Dev Behav Pediatr; 26: $356-360$.

36. Duraphe, V.M. (2015): Management of enuresis: Need to focus on parents' knowledge and practice. International Journal of Nursing Research (IJNR).

37. DiBianco, J.M, Morley1, C., \& Al-Omar, O. (2015): Nocturnal enuresis: A topic review and institution experience. IP: 197.37.95.78. Available at http://www.avicennajmed.com USA.

38. Stover, A.C., Dunlap, G., \& Neff, B. (2008): The effects of a contingency Contracting program on the nocturnal enuresis of three children. Res Social Work Pract; 18(5):421-8. Taiwan. The Journal of Urology.

39. Senbanjo, I.O., Oshikoya, K.A., \& Njokanma, O.F. (2011): Maturational dryness and attitude of parents towards enuresis in children attending outpatient unit of a tertiary hospital in Abeokuta, Southwest Nigeria. UK African Health Sciences; 11(2): $244-251$.

40. Mota, D.M. \& Barros, A.J.( 2008): Toilet training: methods, parental expectations and associated dysfunctions. J Pediatr (Rio J); 84(1): 9-17. 